\title{
Using Blogs to Facilitate Interactive and Effective Learning: Perceptions of Pre-service Arabic Teachers
}

\author{
Suad Al Waely \\ College of Education, Hashemite University, Jordan \\ Ibtehal M. Aburezeq \\ College of Education, Al Ain University of Science and Technology, UAE
}

\begin{abstract}
This study had three primary aims; (i) to explore pre-service Arabic language teachers' perceptions of using the blog as a learning tool, (ii) to identify the defects of collaborating via the blog, and (iii) to modify the use of blogs to facilitate more effective learning. Semi-structured interviews with 14 pre-service teachers in addition to analyzing postings on the course blog were the used methods for collecting data. The results showed that the participants perceived the course blog as a powerful application to enhance their learning through facilitating active interaction with the instructor, peers and course content. However, the results also indicated a number of challenges and defects associated with the blog use for instructional purposes. Discussion of these defects was explored, and suggestions for effective use of blogs were provided.
\end{abstract}

Index Terms — blogs, Arabic language, technology, blended learning, pre-service teachers

\section{INTRODUCTION}

The increasing use of Web 2.0 applications in teaching and learning seems to suggest that teaching the millennial generation may be fundamentally different from traditional approaches. These technologies challenge the conventional conception of pedagogical practices, social space, social practices, and schedules (Brewer \& Klein, 2006; Ajayi, 2009). Web 2.0 as a term refers to the second generation of web technologies that is characterized by user communities and a wide range of services, including social networks, blogs, wikis groove, RSS, and podcasts. Such applications encourage collaboration and efficient exchange of information among users (Master Base, 2010).

Educational literature revealed that Web 2.0 applications have the ability to promote active involvement among students who would be driven to the knowledge construction process (Driscoll, 2002). Moreover, it could develop students' critical thinking skills through practical and insightful activities (Bransford, Brown \& Cocking, 2000; Driscoll, 2002; Karl and James, 2006). Blogs are one of the examples of web 2.0 applications. A blog is an interactive homepage that displays asynchronously developed serial entries, by utilizing simple user interfaces and allowing users to easily maintain content or add new entries, with the features of inserting text, graphics, video and audio (Deng \& Yuen, 2011; Fageeh, 2011; Lai \& Chen, 2010). The blog was defined by McIntosh (2005) as the following:

Historically, a weblog, or 'blog' for short, is recognized by its regularly updated, time and date stamped posts, running down the computer screen in chronologically reverse order (i.e. the most recent post comes first). Crucially, there is an 'Add Comment' feature so that readers of posts can leave their opinions, questions or thoughts. Finally, there is a writing style element: blogs are written by one individual who gives his or her thoughts in a generally relaxed, 'spoken' style (p. 2).

As cited in Fageeh (2011), Kim (2008) considered blogs as an effective replacement for all computer-mediated communication (CMC) applications to language learning. In this regard, Halic, Lee, Paulus, and Spence, (2010) claimed that:

The popularity of blogs among young people has made them tempting to educators seeking to integrate computermediated communication $(C M C)$ tools at university level. These tools are seen as having the potential for enhancing student engagement and providing an environment for collaboration and creation of knowledge ( $p .1)$.

In comparison with other web 2.0 applications, a blog has a number of common features including (1) creating a type of website in an easy, cheap and quick way; (2) organizing content chronologically backwards and by postings which are usually short and frequently posted; (3) allowing readers' voices to be heard through a "comments" feature; (4) instant publishing to the web without having to learn HTML or use a web authoring program; (5) viewing related links; and (6) clearly presenting author's voice and personality (Wu, 2006).

Blogs can be used in teaching and learning for writing reflections on lectures and presentations given in class; as a continuation of classroom discussion; case study discussion, raising questions and answers about processes, procedures, assignments, activities, and topics not addressed during class sessions; and as a resource center for sharing teaching and 
learning aids. In language learning, blogs have been experimentally used as tools to develop writing and reading comprehension skills. Although implications indicate that blogging should not replace face-to-face interaction, it may provide a practice environment where students can think, reflect, and improve language slowly for a real-life audience (Fageeh, 2011; Pinkman, 2005).

Although the blended learning approaches that integrate web 2.0 applications into traditional classes have continued to grow rapidly, it is still at an infant stage of development where the challenge of internalizing such knowledge requires significant amount of time, effort, and planning. In addition, there are incoherent results in terms of effective blog use in educational settings. While several studies (Blackstone, Spiri\& Naganumalogs, 2007; Ellison \& Wu, 2008; Fageeh, 2011; Luce-Kapler, 2007; Lou, Wu, Shih\& Tseng, 2010; Pinkman, 2005; Yang, 2009) have shared a common finding related to the effectiveness of the use of blogs in creating a new rich, engaging, and interactive educational platform supporting student learning and reflections; on the other hand, some studies have indicated that blogs integration technology was useless in terms of enhancing interactivity among students (Divitini, Haugalokken, \& Morken, 2005). Thus, there is a need for further studies to support many of the opinions made about the benefits of blogs use in promoting more active and interactive learning in blended courses. More specifically, researchers and educators need to seriously comprehend how teachers and students perceive and respond to blog applications applied to enhance teaching and learning in traditional classes. Moreover, focused efforts are needed on how best to integrate blogs which can effectively enhance learning and improve achievement.

\section{The Purpose and significance of the Study}

Integrating blogs in teaching languages, especially in English classes, is one of the topics that gained a lot of attention in the educational literature. However, there is a lack of empirical research in the area of integrating blogs in Arabic language teaching and learning classes. Given the fact that Arabic teachers face a lot of challenges in teaching Arabic due to its difficulty, there is a vast need for innovative tools to deliver Arabic language, a tool that attracts students and effectively engages them in the learning process at the same time. In contributing to the body of the research literature, this qualitative study investigated pre-service Arabic teachers' perceptions of using blogs as an interactive tool for enhancing their learning to teach; it also evaluates the pros and cons of collaborating via blogs and how to modify the use of blogs to facilitate more interactive learning.

Molebash (2004) argued that pre-service teachers' perceptions have an impact on their teaching and their decisions of using technologies. Johnson (2007) cited in Ajayi (2009) stated that understanding pre-service teachers' perceptions of their own learning while using technology will help researchers and teachers' educators to gain insights into the relation pre-service teachers make between the theory of using technology for learning and what they actually do in real-life situations. Thus, a clear understanding of pre-service teachers' perceptions regarding blogs will advance researchers' understanding of how technological applications can best enhance teaching and learning through creating meaningful learning activities and tasks that meet students' needs and interests. In addition, the findings of the study will provide a contribution to the literature by understanding factors that effect students' use of blogs as a learning tool.

The Research Questions

- What are the pre-service Arabic teachers' views of the course blog as an interactive learning tool?

- What are the pre-service Arabic teachers' perceptions of the cons of collaborating and interacting via blogs?

- What are pre-service Arabic teachers' suggestions to improve the strategies in which the course blog are used to facilitate interactive learning?

\section{LITERATURE REVIEW}

With technology being more accessible to teachers and students, it is crucial to explore the applications of new technological tools to find practical pedagogical solutions to language learning problems and to enhance teaching and learning of language in general. The integration of text-based asynchronous applications, such as blogs, discussion board, emails, and wikis into language classes may contribute to facilitate this process by allowing students to actively participate in the learning process. They can explore and reflect upon their learning, as well as interact with peers, teachers and content (Castaneda, Ahern, \& Díaz, 2011).

Blogs are one of the rising technologies often used by educators to facilitate communication and collaboration among students (Divitini, Haugalokken, \& Morken, 2005). It is a form of personalized online media or a personal online journal that introduces oneself to others, allows individuals to interact, and shares personal thoughts, information, pictures, movies, activities, and logs in a convenient and easy way (Lou, Wu, Shih \& Tseng, 2010). The theory of blogging instruction is based on constructivism, where instruction is designed to be learner-centered that motivates students to learn, provide variety of active learning opportunities, enhance interaction between students and the instructor and among students themselves, and adopt interactive instruction and multiple assessments (Ku, 2007; Lou, Wu, Shih \& Tseng, 2010).

Similarly, Nardi, Schiano, Gumbrecht, \& Swartz (2004) noted that blogging contributed in creating a sense of community that would be difficult to take place in a traditional classroom setting. Dieu (2004) stated that blogging gives students an opportunity to "maximize focused exposure to language in new situations, peer collaboration, and contact with experts" (p. 26). Students in such context are required to communicate closely with a particular group of classmates. Moreover, the communication can be during class time or at their leisure time. This blend of planned and 
spontaneous communicative exchanges inside and outside the classroom makes blogging a meaningful and engaging social exercise (Blackstone, Spiri\& Naganumalogs, 2007).

On the contrary, some studies revealed that integrating blogs into teaching and learning contexts has no value in enhancing students' motivation to become more involved in the learning process (Divitini, Haugalokken, \& Morken, 2005; Williams \& Jacobs, 2004). According to Williams and Jacobs (2004), a significant number of participants indicated that blogging activities are not useful. In another study conducted by Xie and Sharma (2004), Students showed negative and positive ideas regarding blog use. They considered blogs as a helpful tool for learning and thinking. However, the availability of their contributions to everyone in the class gave them a feeling of anxiety and insecurity.

Along with these conflicting results in terms of the effectiveness of blogs in enhancing interactive learning, it is important to remember that the efforts of effective technology integration in schools are of little value if they do not take the pre-service teachers and in-service teachers into account (Ishtaiwa \& Shana, 2011). Research literature has suggested that if teachers believed that technology does not fulfill their own and their students' needs, then most likely they will not attempt to implement it into their classes (Johnson, 2007; Molebash, 2004). According to Schellens, Van Keer, \& Valcke (2005), the challenge, difficulty, and motivation of a learning task are defined by individuals' perceptions.

Concerning the perceptions towards blog use, Shoffner (2006) in his qualitative study concentrated on the potentiality of blogs for informal reflection. The analysis of learners' logs, focus group interviews and individual interviews with a group of pre-service teachers revealed positive results in terms of the impact of blogs on their reflective practice. The major positive features of blogs are their informality, accessibility through the Internet and ability to support online communal interactions.

Similarly, Wang, Hsu and McPherson (2006) investigated the effects of blogging on pre-service teachers' awareness of diversity in a literacy/reading context. The analysis of quantitative and qualitative data collected from 24 pre-service teachers revealed that blogging: (1) allows to share knowledge and experiences as well as express feelings and thoughts, (2) enables to be aware of peers' opinions and confronting perspectives, (3) facilitates and deepens reflective practices, (4) bridges the disconnection between theory and practice, and (5) provides a learning environment where there is no restraint on time to think over the discussion topics compared to in-class discussion.

Kuzu, (2007) investigated the impact of course blog on supporting instruction and sustaining social interaction. Based on conducting semi-structured interviews with 10 pre- service teachers, it was found that participants valued the use of blogs to enhance their interaction with peers and the course instructor. In their description of pre-service teachers' perceptions and experiences of blogging in a web-based course, Demirel, Duman, Incesu, and Goktas, (2008) noted that students enjoyed blogging and felt complemented. They also indicated that blogging enriched their pre-service education through providing them with a motivating tool for enhancing communication and knowledge sharing. Nevertheless, students have negative perceptions about templates and memory field of the application. In another study, Yang (2009) explored the use of blogs to improve critical reflection. Based on date collected from Forty-three preservice teachers who used blogs as a reflective platform, it was concluded that the technology is a valuable tool for reflection and communication with others.

In terms of studying the effect blogs bring to language instruction, Lou, Wu, Shih and Tseng (2010) conducted an experimental study to examine the impact of adopting blogging upon Chinese language composition instruction in a vocational high school in Taiwan. Forty students were randomly selected to serve as participants. The results revealed that utilizing blogging in Chinese language composition can positively enhance students' composition learning; and facilitate more effective instructor-student interaction, which enhances participants' learning motivation and compositional ability. Moreover, participants possessed a positive attitude toward the instructional model of using blogging in Chinese language composition instruction.

In a similar study, Fageeh (2011) sought to identify the effectiveness of blogging in developing writing skills and improving attitudes towards English learning. Participants were Writing Class students in a college in Saudi Arabia. An experimental research method and a descriptive research design were employed to answer the research questions. The findings indicated that the students perceived blogging as a beneficial tool for developing their writing proficiency and their attitudes towards writing. They noted that using a blog gave them an opportunity to freely express their ideas and thoughts in English, write for a wider audience, and maintain an interactive relationship with a real time readership.

The literature review shows that pre-service teachers considered blogs an advantageous learning tool that may lead to a number of positive effects on the teaching and learning process, where learners enjoy a high level of autonomy and opportunity for greater interaction with the peers and instructor. But like any other medium, blogs have some shortcomings such as the feeling of insecurity that participants expressed. Al-Fadda and Al-Yahya (2010) raised other issues that limit students' interaction and collaboration via blogs such as lack of time, class size, quality of students' posts, and lack of instructor presence. This, in turn, suggests that the key to success in adopting blogs rests not on the content being presented, but indeed on the method by which the content is being delivered. Thus, it is vital to realize how this success can be achieved. Pre-service teachers can provide important insights by describing their perceptions of the impact of blogs technology on learning that might lead educators to create efficient, flexible and interesting blogging activities. 


\section{METHODOLOGY}

\section{Research Context and Participants}

This study was carried out at Al Ain University of Science and Technology (AAU) in the United Arab Emirates (UAE) as a response to the encouragement from its administration to faculty members to adopt modern technology as an integral part of their instruction methods. The present case study was conducted at the Program of Professional diploma in Teaching.

An educational blog was created as a new and additional component to Methods of Teaching Arabic course (EDU 532) over 14 weeks. In addition to the daily face-to-face class meetings, students were requested to make both collaborative and individual weekly contributions to the course blog supported by Google Blogger. The course instructor prepared the students to use the different capabilities and functions of the course blog. The blog tool was mainly adapted for allowing pre-service teachers to post educational and meaningful content related to Arabic language teaching and learning, support their posts with resources (videos, audios, pictures, websites,...etc), discuses course content, generate questions, reply to questions, and comment on daily lectures.

In order to promote pre-service teachers to engage in productive interaction and in-depth discussions rather than random postings, they were asked to meet specific posting requirements. At the beginning of the semester, a set of instructions and assessment criteria were distributed. The criteria included the following:

- Contributions should be related to EDU (532) course syllabus.

- Contributions should include new ideas, opinions and critical thinking, rather than focusing on repeating, describing or summarizing others ideas and thoughts.

- Each pre-service teacher is expected to post at least two messages per week.

- Replying to the instructor and peers' questions should be within 24 hours.

The goals of the previous blended design were: enhancing pre-service teachers' learning to teach Arabic language by fostering interaction (student-student, student-instructor, and students-content), and contributing to a critical understanding of the course material. The course instructor's role included responding to students' questions, giving feedback, providing additional ideas and concepts. He produced 28 records under different titles where 21 of them were enriched with students' ideas and comments. In addition, the instructor was responsible for evaluating students' messages based on the provided criteria.

Due to the fact that almost all UAE universities provide separate sections for males and females, The investigation covers all female pre-service Arabic teachers $(n=68)$ registered into three sections of EDU 532 during the first semester of 2010/2011. In selecting the study sample, 14 female pre-service teachers originally were selected randomly using a list of students' names. They were personally contacted by the second researcher to request participation. Fortunately, all selected pre-service teachers accepted to participate in the study.

\section{Data Collection and Procedures}

Two types of data collection methods were used. They were semi-structured interviews and analysis of participants' posts on the course blog. The interview questions were developed from the literature review, research questions, in addition to the researchers' experience in the field. They concentrated on the following areas:

- Pre-services' views of blog as a tool to enhance interactive learning;

- Pre-services' views of the pros and cons of collaborating and interacting via blogs;

- Pre-services' views of the required assignments related to the course blog use, and;

- Pre-services' views of the suggestions for modifying the use of blogs in teaching and learning.

The interview questions were validated by a panel of experts in the fields of curriculum and Arabic instruction, educational technology, and research and evaluation. This led to further revisions and modifications. In addition, the second researcher interviewed three pre-service Arabic teachers not participating in the actual study, which helped to further rephrasing of the questions.

According to Hitchcock and Hughes (1995), one of the important elements of successful qualitative research is establishing strong and effective relationships between the researchers and participants. This requires developing a sense of friendship between them that leads to trust and confidence. Consequently, it helps the researchers to get more information from participants and ensure confidentiality. Therefore, an orientation meeting was held with all participants to explain the purpose of the study, and the data collection details to ensure confidentiality, and to get preservice' approval to use their comments for scientific research. Each interview lasted for 15 to 34 minutes. The substantive phases of data collection were audio-taped and transcribed into Arabic in which participants communicate. Recording interviews assured having the most complete record of what was said as advised by Hitchcock and Hughes (1995).

The secondary data collection method for this study was collecting participants' posts on the course blog such as posted questions, answers and comments. Both the interviews transcripts and participants' posts were transferred to a computer file.

Data Analysis

Miles and Huberman's (1994) data analysis guidelines were used. These guidelines include creating codes for the field notes, noting any reflections or remarks in the margins, creating codes for identifying similar patterns, themes, and 
common sequences in the data set, and creating a set of generalizations that derive from the available data. Additionally, the researchers followed the data reduction method by eliminating all information that was not relevant to the research questions, summarizing ideas, categorizing similar patterns, and paraphrasing stories (as cited in Ishtaiwa \& Shana, 2011).

To judge the value of the qualitative data, the internal and external validity were addressed in this study. According to Merriam (1998) cited in Ishtaiwa (2011), Internal validity in qualitative data is defined as pertaining to how closely the findings match reality. Internal validity was conducted by using, peer debriefing techniques and member checking to validate the descriptions of the data and the interpretations (Ishtaiwa, 2011). On the other hand, external validity is "concerned with the extent to which the findings of one study can be applied to other situations" (Merriam, 1998, p. 207). It can be increased through rich and thick description. In this study, significant number of typical quotations was utilized to provide as much thick description as possible while addressing all of the diverse aspects of our findings (Ishtaiwa, 2011).

\section{Results OF THE StUdy}

\section{Participants' Views of the course blog}

Pre-service Arabic teachers perceived the course blog as primarily positive in terms of potentiality to enhance their learning to teach Arabic language. Among 14 participants, 11 (79\%) indicated that the course blog has a number of educational benefits. Most notably is promoting collaborative and interactive learning communities that led them to develop better and faster understanding of the course content; remember and retain more information; enhance their social interaction; and improve their learning and critical thinking skills.

More specifically, the findings revealed a total of 35 positive opinions and comments regarding the blog use. These opinions were summarized under six themes including (a) fostering effective interaction with the instructor, peers, and the instructional content, (b) experiencing an attractive and interesting learning environment, (c) accessing to variety of learning resources, (d) allowing more time to think, reflect and respond, (e) discussing interesting or complicated topics in details, and (f) breaking down the barrier of shyness. The themes, frequencies and percentages are presented in Table 1 .

TABLE 1:

POSITIVE THEMES REGARDING BLOG USE

\begin{tabular}{|l|l|l|}
\hline Themes & Frequency & Percentage \\
\hline Fostering effective interaction with the instructor, peers, and the instructional content & 12 & $34 \%$ \\
\hline Experiencing an attractive and interesting learning environment & 8 & $23 \%$ \\
\hline Accessibility to a variety of learning resources & 5 & $14 \%$ \\
\hline Allowing more time for thinking, reflecting and responding & 5 & $14 \%$ \\
\hline discussing interesting or complicated topics in details & 3 & $9 \%$ \\
\hline Breaking down the barrier of shyness & 2 & $6 \%$ \\
\hline
\end{tabular}

This previous findings were evident in the participants' typical responses, such as:

- "The course blog was really beneficial for me. It enhances my learning to teach Arabic language by allowing me to understand the course content in a better and deeper way. I had the opportunity to discuss what we studied in class and inquire about what I did not understand. The course instructor and my peers were always there to help me clarify things."

- "Using the course blog helped me improve my learning as well as increase my interest in the course. Blogging is very different from face to face instruction. It allowed us to discuss and share what we learn in class in a more enjoyable and interesting environment. I really enjoyed reading others thoughts and browsing posted links to expand my knowledge and understanding of issues related to teaching Arabic language."

- "This was the first time I use online technology to learn. One of things that I appreciate in such environment is the access to additional and supplementary materials and learning resources provided by the instructor or peers. Learning from different resources helped me to think more critically and see things differently."

- The asynchronous nature of blogging was beneficial for me. Its major advantage is giving me more time for reading, thinking and reflecting before posting my answers. The process of writing responses enhanced my contributions to the course discussions. Unlike speaking, with writing there is plenty of time to think and correct myself before posting the final response. In addition, there is no reason to be shy."

- "What I actually like about blog use is providing us with the opportunity to discuss all topics that we covered in class, what we could not cover, what we understood, and what we could not understand. There is a plenty time to engage in deep and rich discussions of complex, interested and related issues without hesitation, shyness or being afraid of wasting the class time."

The previous finding generated from interviews conducted with participants was supported by analysis of all participants' posts on the course blog. During the 14 weeks of the study, participants posted 439 posts which were categorized under six major themes. They were (a) responding to peer's questions, (b) responding to instructor's questions, (c) posting related and supplementary materials, (d) asking questions, (e) commenting on lectures or 
presentations given in class, and (f) inquiring about explanations and clarifications. The themes, frequencies and percentages are presented in Table 2 .

TABLE 2:

THEMES REGARDING PARTICIPANTS' POSTS

\begin{tabular}{|l|l|l|}
\hline Themes & Frequency & Percentage \\
\hline Responding to peer's questions & 141 & $32 \%$ \\
\hline Responding to instructor's questions & 94 & $21 \%$ \\
\hline Posting related and supplementary materials & 78 & $18 \%$ \\
\hline Asking questions & 55 & $13 \%$ \\
\hline Inquiry for explanation and clarifications & 40 & $9 \%$ \\
\hline Comments on lectures or presentations & 31 & $7 \%$ \\
\hline
\end{tabular}

On the other hand, three participants $(21 \%)$ provided negative comments regarding the use of the course blog as a tool to learn teaching Arabic language. They indicated their preference of face to face environment in comparison to blogs. As pointed out by a participant: "Why should we use such complicated tool which requires more time and effort to participate, I like face to face learning where you can get an immediate feedback." Another participant mentioned "I do realize that technology is an essential part of teaching and learning in my future career. However, I do not think that blogging is a good choice. If I have to use technology to contact the instructor and my peers, I prefer to use my personal email. It is easier and more private."

Pre-service Arabic teachers' views of the cons regarding the use of the course blog

Like any other technological application, utilizing blogs in education has its defects. In order to identify these defects from pre-service Arabic language teachers' point of view, Participants were asked about the cons and defects of collaborating and interacting via the course blog. Participants raised several concerns and issues including: extra workload, nature of students' responses, need for high level of technological skills, lack of immediate feedback, and lack of security and privacy.

Out of 14 participants, 12 respondents $(86 \%)$ indicated that the use of the course blog had a major impact on their workload. They concluded that the amount of required work has dramatically increased as a result of adding more tasks to their workload. They were required to read a lot of materials, summarize, think, browse the Internet, download and upload related materials, and type responses and comments. Such activities need considerable amount of time and effort. This concern was evident in the participants' typical responses, such as:

- "Blogging has many advantages for me, for instance, it enabled me to read several perspectives and opinions. However, reading others' comments needs a lot of time and effort which I did not have. My schedule was always booked with other requirements."

- "One of the blogging defects is increasing my workload. Reading my classmates' numerous posts, summarizing them and formulating my own response is alot of work. In addition, I'm a slow typist needing much time and effort to type the required assignments."

- "I'm so happy with the idea of implementing blog technology in my learning to teach. It has positively impacted my productivity. However, the success in this new environment needs a lot of effort, as there are lots of things to be done."

- "Actually, using the course blog increased the burden of my study. As a student, I'm looking for something that helps me without increasing my workload. Unfortunately, using blogs in education means extra work, effort, and time to learn using this new application."

Related to the first concern, 11 participants (79\%) noted that the nature of students' responses presented an important defect of blog use. They reported their frustration of reading the same idea being repeated because some students tend to copy what other students have posted without giving different opinions or perspectives. The following typical participants' responses give a good description of this issue:

- "Some students post others' comments with minor changes. It means that you spend huge effort and time in reading the same thing many times. In this case, blogging is boring, time consuming and strenuous."

- "There should be different ways to exploit our effort rather than feeling boredom of reading repeated and irrelevant comments."

- "The bad thing about this issue is spending much of your energy on reading disconnected ideas. I noticed that some of my classmates posted their responses only to get the participation grade without paying any attention to the quality of their posts."

- "Most of the posted opinions are very short."

The analysis of students' postings supported this finding. It was noticed that the same idea is being written repeatedly. For example, in responding to one of the instructor's questions "what is the best teaching technique to teach students how to conclude the main ideas of the lesson?", nine participants posted the same answer which was "collaborative learning is recommended technique."

In regard of the third defect, the need for high level of technological skills, it was raised as a major defect of using the course blog. As perceived by nine pre- service Arabic teachers (64\%), the lack of skills of mastering and utilizing new technology presents an important challenge to achieve the positive results of blogging activities. Nine participants 
admitted that they do not possess the adequate skills and ability to apply the new technological applications effectively. One participant explained this issue by saying: "Integrating blog in teaching and learning process is a powerful way that can motivate students and provide them with variety of information resources. But achieving such promised results requires high level of technology literacy and skills which actually I do not have. For example, although our instructor showed me how to upload a PowerPoint presentation, I could not upload it successfully." Another participant said: "I believe in technology and its positive impact on teaching and learning. However, my experience in using computer technology is limited; I need a lot of effort, time and training before being able to communicate via the blog tool effectively." One more participant expressed her feeling toward this issue stating: "Why should we have to use this complicated application?!! The email is easier and more private to communicate and interact with each other."

As for the fourth point, although students were required to reply to the instructor and peers' questions within 24 hours, five participants (36\%) considered this period of waiting for others to respond to their questions and requests as a defect of interacting via the course blog. They recommended adding synchronous tools such as instant messaging and video conferencing as they will enhance the effectiveness of technology integration in teaching and learning. Participants reported that synchronous tools in comparison to asynchronous ones will help them to engage in simultaneous dialogue and provide them with immediate feedback which is necessary to monitor the clarity and accuracy of their understanding. A participant commented "Personally, I like communicating via synchronous tools more than asynchronous ones. Synchronous format is just perfect in term of giving you an immediate response and feedback to ensure clear understanding of presented ideas." Another participant said: "Waiting for responses for my questions was annoying. The lack of immediate feedback is a major shortcoming of the course blog. Students usually wait to the last minute to respond, you even need to put in your mind; it is possible that you won't receive any response."

Finally, the lack of privacy when posting on the course blog was considered as another defect. Four participants (29\%) indicated that they were anxious because they do not want their contribution to be available to everybody. This feature of blogs gave them a feeling of lack of confidentiality. As evident, a participant expressed her feeling: "In every single time 1 posted something on the blog, I felt nervous as a result of the fact that my opinions will be read from all my classmates." Another participant noted: "Unlike the course blog, sending an email to the instructor or to a classmate gives me a feeling of privacy. By email I could ask about anything without fear or timidity."

\section{Pre-service Arabic teachers' suggestions to improve the use of the course blog}

In this study, students were provided with a set of instructions and assessment criteria to enhance the quality of their postings. During the interviews, participants were asked about their views of these criteria to improve their use of the course blog. Participants provided mixed views about the effectiveness and efficiency of the criteria of blog use in term of enhancing their interaction and learning in this course. Eight participants (57\%) considered these criteria as a powerful way to enhance their understanding and learning of the course materials. The following are some of the suggestions provided by the participants:

- "When the instructor talked with us about the course blog in the beginning of the semester, I got very scared of the complicated thing he was talking about. However, the criteria and guidelines used helped me a lot in implementing this amazing application. I can confidently say that two messages a week is more than enough to help a novice technology user like me to post good contributions."

- "Although it was the first time to use blogs for learning purposes. I'm happy with that use. Being required to post new ideas and opinions had the advantage of making me think in a critical way."

- "When I become an Arabic language teacher, I will use blogs in my teaching. In addition, I will use the great criteria that we were required to follow. It is fantastic in term of giving opportunity to all students to participate."

- "I remember that one of the requirements was replying to the instructor or peers' questions within 24 hours. I think this was a reasonable time limit."

On the other hand, 6 participants (43\%) expressed their dissatisfaction with the contribution criteria that used in this study. They concluded that these criteria were not detailed enough to help them write qualitative posts. In this regard, participants concentrated on five major suggestions to improve the effectiveness and efficiency of the blog use as an interactive learning tool. These suggestions were (1) providing them with evaluation criteria, (2) focusing on discussing specific issues, (3) deleting irreverent and repeated comments, and (4) providing them with technical support, and (5) allowing them to use assumed or nicknames instead of their real names. The following are some responses regarding these suggestions:

- "In many times, I did not know what and how much exactly should I write. Many things were missing in term of the used criteria. Knowing how much I'm required to write and how my responses will be evaluated would help me to give better responses."

- "As a result of getting the same grade regardless the content of our posts, it was obvious that some students were posting only for getting the posting grade. This led to a huge amount of useless comments. I think having a clear evaluation criterion to reward the good responses would motivate students to pay more attention."

- "Asking us to post about specific issues is more beneficial than posting general ideas. Discussing specific ideas is powerful in enhancing our critical thinking and reflection." 
- 'Reading my peers' comments before posting my response was significant to me, it helped me see things differently. However, reading others' comments is cumbersome and boring. I was required to read tens of repeated and sometimes irreverent comments. I would suggest deleting all repeated and irreverent comments on a regular basis, which will save time, effort, and enhance the quality of the postings"

- "This was the first time I use the blog tool. We were asked to perform many tasks. On a personal level, I did not have prior experience and knowledge of most of these things. Besides that, I faced a lot of technical problems during the semester. To succeed in such activities, we need someone to show us how to implement this application and to provide us with some technical support."

- "I think one of the disadvantages of interacting via the course blog was forcing us to use our real names. Whenever I posted on the blog, I did not feel comfortable because my identity was revealed to all classmates. I think it would have been better if the instructor gave us nicknames as it would have made us feel more comfortable."

\section{DISCUSSION}

The aim of the current study was to explore pre-service teachers' views of using the course blog as a tool for enhancing their learning to teach Arabic language. It also aimed to identify the pros and cons of collaborating via the course blog and how to modify its use to facilitate interactive and effective learning. Based on conducting interviews with 14 pre-service Arabic teachers and analyzing their postings on the course blog, some notable themes emerged that will be further explored.

Pre-service Arabic language teachers view the course blog as a functional and valuable tool for enhancing their learning to teach. The participants' self-evaluation of the impact of the course blog indicated that this tool has the advantage of improving learning and understanding of the course content through offering them a variety of instructional benefits. The positive participants' view towards the impact of the course blog on improving learning and understanding is due to the opportunity for interaction and reflection the tool offered. Unlike traditional teaching where the instructor or a few students may dominate the discussion, the blog allows all voices to be heard. Even those students who may be intimidated by speaking in front of their peers, or those who need more time to respond are easily able to express their thoughts more freely and descriptively (Black, 2005). As described by one participant: "The process of writing responses enhanced the quality of my contributions to the course discussions. Unlike speaking, writing provides plenty of time to think and correct my comments before posting it. In addition, there is no reason to be shy."

According to Berge and Collins (1995), text-based communications have the power to enhance interactions through removing and diminishing barriers of participation such as lacking communication skills, cultural differences, and shyness. Interaction is a powerful facilitator for learning, and there is a relationship between the amount of interaction students have with course content and their performance. More specifically, interaction serves as a purpose of increasing participation \& motivation, developing communication, receiving feedback, enhancing elaboration \& retention, supporting learner, discovery\& exploration, clarifying misunderstanding, and achieving closure (Wagner, 1997). Blogs involve all of the above functions and characteristics.

This finding is consistent with the findings of other studies that focused on pre-service teachers' perceptions of blogs such as Shoffner (2006), Wang, Hsu \& McPherson (2006), Kuzu (2007), Demirel, Duman, Incesu, \& Goktas (2008), and Yang (2009). It was evident that participants in all these studies had positive views toward the use of blogs as a teaching and learning tool.

Although blogging environments have a more flexible and independent structure in comparison to traditional face-toface learning environments, addressing problems occurred in such environments is relatively more difficult than dealing with the problems of traditional teaching (Kuzu, 2007). In this study, pre-service teachers identified a range of shortcomings that might limit the effective use of blogs for instructional purposes; including: (i) extra workload, (ii) nature of students' responses, (iii) need for high level of technological skills, (iv) lack of immediate feedback, and (v) lack of security and privacy. To address these defects and problems of blogging instruction, pre-service teachers offered several suggestions for more effective, thoughtful, and reflective blog use. These suggestions were (a) providing evaluation criteria, (b) focusing on discussing specific issues, (c) deleting irreverent and repeated comments, (d) providing technical support, and (e) using nicknames.

Utilization of blogs in education is a type of providing online activities that require many resources to be introduced and delivered. Conducting such activities effectively requires innovation, creativity, enthusiasm, desire, appropriate infrastructure, and adequate preparation for both teachers and students. In addition, the effective use of blogs as an integral part of instruction requires precise planning and well preparation. Thus, teachers have the key role in planning and implementation of blog activities. They need to make decisions regarding more well-organized, flexible and attractive uses of blogs in their instruction (Kuzu, 2007). In this aspect, Black (2005) offered some recommendations that can be followed to improve the quality of asynchronous discussion. They include the following:

- Specific instructions and evaluation rubrics for students' responses.

- Giving examples of what considered a "reflective piece."

- Well-made open-ended questions.

- Requirement of specific connections made to the readings. 
- Private notes to students who behave inappropriately or change the topic.

- Summary of the discussion.

- Accountability (Black, 2005).

For pre-service preparation, providing experiences in instructional design, media selection, modeling exemplary technology practices, resource sharing, and extensive and sustained training and practice is a significant step to achieve good results in term of technology use (Earle, 2002). In this regard, it is crucial to realize that it is not enough knowing how to use technology; instead, pre-service teachers are required to be knowledgeable of technology and self-confident to integrate it effectively. Getting the advantages of technology integration depends on knowledgeable and enthusiastic individuals who are motivated and prepared to utilize technology to achieve instructional purposes (Shamoail, 2005).

Pre-service teachers' previous experiences with the blog use, their readiness for technology-supported instruction and their attitudes towards such a tool should be examined beforehand (Kuzu, 2007). It was obvious in some participants' responses that they do not prefer the blog due to lack of skills and knowledge of using it, and lack of security and privacy. Addressing such issues may lead to fruitful learning outcomes.

\section{CONCLUSION AND IMPLICATIONS}

The use of digital technologies in formal education has added flexibility to the teaching and learning process and offered opportunities for informal learning behavior. In terms of flexibility, the new technology can provide an interactive environment whereby students could collaborate and share knowledge freely and without traditional obstacles such as time and place. Blogs have been considered among these technologies that provide powerful technique for students learning through helping them to develop better and faster understanding of the course content; remember and retain more information; enhance their social interaction; and improve their learning and critical thinking skills. However, there is a number of challenges and defects associated with the blog use in instructional settings. In other words, the use of blog in education is a problematic issue due to technical or pedagogical factors. Meeting these challenges will define the effectiveness of the blog use as a means for supporting instruction.

Based on the findings of this study, a number of implications were offered in order to achieve a better result in term of using blogs to support teaching and learning in blended courses. First of all, educational institutions need to encourage and motivate faculty members to utilize blogs in their instruction. As mentioned earlier in this paper, the instructor plays a significant role in technology integration. So teachers should be motivated to use the new technology through different types of motivating incentives.

Second, pre-service teachers should be given the opportunity to familiarize themselves with and experiment new technology applications, share ideas and collaborate with each others on new technology projects and uses (Ishtaiwa \& Shana, 2011). Although participants in this study pointed out that this was their first experience in using blog for instructional purposes, they were happy with it. Pre-service teachers should also be encouraged to participate in new technology evaluations that can support their own teaching and learning growth. Effective technology integration demands a strong commitment from both instructors and students.

Third, educational institutions should provide professional development programs for instructors and students that concentrate on effective use of new technological applications. Participants indicated that among the defects of blog use were type of students' responses, the need for high level of technological skills and lack of immediate feedback. These problems could be due to the lack of experience in structuring and implementing blogging activities. Training programs could help faculty and students alike create and implement more meaningful online activities.

Fourth, addressing the challenges of the blog use is highly recommended. Many pre-service teachers may resist technology for many reasons, including lack of technological skills, and lack of time to learn, plan and practice. Addressing such issues surely will motivate them to integrate this technology more effectively.

Finally, additional research is needed to examine and explore other issues related to blogs use such as the impact of blog on achievement in specific areas such as Arabic language, the effects of blog use on acquisition of language skills, students' perceptions of learning blogs use, comparing between the use of blog and other media, and the ways of evaluating students' postings on the course blog. Such studies may lead to more efficient use of blogs for instructional purposes.

\section{REFERENCES}

[1] Al-Fadda, H., \& Al-Yahya, M. (2011). Using web blogs as a tool to encourage pre-class reading, post-class reflections and collaboration in higher education. US-China Education Review, 7(7), 100-106. Retrieved December 19, 2010, from http://www.teacher.org.cn/doc/ucedu201007/ucedu20100710.pdf.

[2] Ajayi, L. (2009). An Exploration of Pre-Service Teachers' Perceptions of Learning to Teach while Using Asynchronous Discussion Board. Educational Technology \& Society, 12 (2), 86-100.

[3] Berge, Z., \& Collins, M. (1995). Computer-mediated communication and the online classroom: Overview and perspectives. Cresskill, New Jersey: Hampton Press.

[4] Black, A. (2005). The use of asynchronous discussion: Creating a text of talk. Contemporary Issues in Technology and Teacher Education, 5 (1), 5-24. 
[5] Blackstone, B., Spiri, J., \& Naganuma, N. (2007). Blogs in English language teaching and learning: Pedagogical uses and student responses. Reflections on English Language Teaching, 6(2), 1-20.

[6] Bransford, J.D., Brown, A.L., \& Cocking, R. R. (Eds.). (2000). How people learn: Brain, mind, experience, and School. Washington D.C.: National Academies Press.

[7] Brewer, S. \& Klein, J. (2006). Types of positive interdependence and affiliation motive in an asynchronous, collaborative learning environment. Educational Technology, 54 (4), 331-354.

[8] Castaneda, D., Ahern, T., \& Díaz, S. (2011). Teaching and learning the Spanish aspect using blogs and wikis: An exploratory study. IALLT Journal of Language Learning Technologies, 41 (1), 64-89. Retrieved December 12, 2010, from http://www.iallt.org/sites/default/files/Castaneda11.pdf.

[9] Demirel, T., Duman, D., Incesu, S., \& Goktas, Y. (2008). Using Blogs (Weblogs) in Higher Education: Toys or Tools. Kuzu. A, Odabasi. Paper presented at the International Educational Technology Conference 2008, Eskisehir, Turkey, $1114-1117$. Retrieved January 11, 2011, from http://ietc2008.home.anadolu.edu.tr/ietc2008/219.doc.

[10] Deng, L. \& Yuen, A. (2011). Towards a framework for educational affordance of blogs. Computers \& education, 56(2), 441451.

[11] Dieu, B. (2004). Blogs for language learning. Essential Teacher, 1(4), 26-30.

[12] Divitini, M., Haugalokken, O., \& Morken, E. M. (2005). Blog to support learning in the field: Lessons learned from a fiasco. Proceedings of the Fifth IEEE International Conference on Advanced Learning Technologies (ICALT'05), 219 - 221.

[13] Driscoll, M. (2002). How people learn (and what technology might have to do with it). (ERIC Document No. ED470032). Retrieved January 2, 2011, from http://www.ericdigests.org/2003-3/learn.htm.

[14] Earle, R. (2002). The Integration of Instructional Technology into Public Education: Promises and Challenges. ET Magazine, 42(1), 5-13. Retrieved March 19, 2011, from http://BooksToRead.com/etp.

[15] Ellison, N. \& Wu, Y. (2008). Blogging in the Classroom: A preliminary exploration of student attitudes and impact on comprehension. Journal of Educational Multimedia and Hypermedia, 17(1), 99-122.

[16] Fageeh, A. (2011). EFL learners' use of blogging for developing writing skills and enhancing attitudes towards English learning: an exploratory study. Journal of Language and Literature, 2(1), 31-48. Retrieved January 2, 2011, from http://www.lit.az/ijar/pdf/j11/5/JLL2011(1-5).pdf.

[17] Halic, O., Lee, D., Paulus, T. \& Spence, M. (2010). To blog or not to blog: Students' perceptions of blog effectiveness for learning in a college-level course. Internet and Higher Education, 13(4), 206-13.

[18] Hitchcock, G., \& Hughes, D. (1995). Research and the Teacher: A QualitativE Introduction to School- Based Research (2nd ed.). New York: Routledge.

[19] Ishtaiwa, F. (2011). Faculty Attitudes and Use of Moodle Course Management System as a Supplement to Face-to-Face Instruction: A Jordan Case Study. Journal of Educational and Psychological Sciences, 12 (1): 11-44.

[20] Ishtaiwa, F. \& Shana, Z. (2011). The use of interactive whiteboard (IWB) by pre-service teachers to enhance Arabic language teaching and learning. Learning and Teaching in Higher Education: Gulf Perspectives, 8(2), 1-18.

[21] Johnson, H. (2007). Dialogue and the construction of knowledge in E-learning: Exploring students' perceptions of their learning while using blackboard asynchronous discussion board. Retrieved December 15, 2010 from http://www.eurodl.org/materials/contrib/2007/Henry_Johnson.htm.

[22] Karl, L., and James, J. (2006). Students' perceptions of online learning: A comparative study. Journal of Information Technology Education, 5, 201-219. Retrieved November 20, 2010, from http://www.jite.org/documents/Vol5/v5p201219Smart54.pdf.

[23] Kim, H. (2008). The phenomenon of blogs and theoretical model of blog use in educational contexts. Computers \& Education, 51(1), 1342-1352. Retrieved November 29, 2010, from http://etec.hawaii.edu/otec/classes/645/sdarticle.pdf.

[24] Ku, C. J. (2007). Blog and project-based learning. Teachers' Voice: National Educational Association Monthly, ROC, 197, 2427.

[25] Kuzu, A. (2007).Views of pre-service teachers on blog use for instruction and social interaction. Turkish Online Journal of Distance Education-TOJDE, 8(3), 34-51. Retrieved November 28, 2010, from http://tojde.anadolu.edu.tr/tojde27/pdf/article_2.pdf.

[26] Lai, H. \& Chen, C. (2010). Factors influencing secondary school teachers' adoption of teaching blogs. Computers and education, 56(4), 948-960.

[27] Luce-Kapler, R. (2007). Radical Change and Wikis: Teaching New Literacies. Journal of Adolescent and Adult Literacy, 51(3), 214-223.

[28] Lou, S., Wu, S., Shin, R., and Tseng, K. (2010). Adoption of blogging by a Chinese language composition class in a vocational high school in Taiwan. Australasian Journal of Educational Technology, 26(6). 898-916.

[29] Master Base. Retrieved March 1, 2010, from http://www.en.masterbase.com/support/glossary.asp.

[30] McIntosh, E. (2005). From learning logs to learning blogs. Scottish Centre for Information on Language Teaching and Research. Retrieved November 25, 2010, from http://edu.blogs.com/edublogs/files/slr_part_2_blogs.doc.

[31] Merriam, S. (1998). Qualitative research and case study applications in education. San Francisco: Jossey-Bass.

[32] Miles, M., \& Huberman, A. (1994). Qualitative data analysis: An expanded Sourcebook (2 ${ }^{\text {nd }}$ ed.). Thousand Oaks, CA: Sage.

[33] Molebash, P. (2004). Pre-service teacher perceptions of a technology-enrich methods course. Contemporary Issues in Technology and Teacher Education, 3(4), 412-432.

[34] Nardi, B., Schiano, D., Gumbrecht, M., \& Swartz, L. (2004). Why we blog. Communications of the ACM, 47(12), 41-46.

[35] Pinkman, K. (2005). Using blogs in the foreign language classroom: Encouraging learner independence. The JALT CALL Journal, 1(1), 12-24. Retrieved December 27, 2010, from http://jaltcall.org/journal/articles/1_1_Pinkman.pdf.

[36] Shamoail , E. (2005). Teachers' perceptions and experiences in adopting "Blackboard" computer program in a Victorian secondary school: A case study. Doctoral Dissertation, Victoria University, 2005. 
[37] Schellens, T., Van Keer, H. \& Valcke, M. (2005). The impact of role assignment on knowledge construction in asynchronous discussion groups. Small Group Research, 36 (6), 704-745.

[38] Shoffner, M. (2006). We don't have the liberty of being brainless: Exploring pre-service teachers' use of Weblogs for informal reflection. Dissertation Abstracts International, (UMI No. 3207340).

[39] Wang, S., Hsu, H-Y., \& McPherson, S. (2006). Using Blogs to Facilitate Online Discussion. Proceedings of World Conference on E-Learning in Corporate, Government, Healthcare, and Higher Education, 998-1001, Retrieved January 15, 2011, from. http://iris.nyit.edu/ hhsu02/paper/blog.pdf.

[40] Wagner, E. D. (1997). Interactivity: From agents to outcomes. New Directions for Teaching and Learning, 71, 19-26.

[41] Williams, B.J., \& Jacobs, J. (2004). Exploring the use of blogs as learning spaces in the higher education sector. Australasian Journal of Educational Technology, 20(2), 232-247. Retrieved December 28, 2010, from http://www.ascilite.org.au/ajet/ajet20/williams.html.

[42] Wu, C. (2006). Blogs in TEFL: A new promising vehicle. US-China Education Review, 3(5), 69-73.

[43] Xie, Y., \& Sharma, P. (2004). Students lived experience of using weblogs in a class: An exploratory study. Proceedings of the Annual Conference for the Association for Educational Communications and Technology, 839-846.

[44] Yang, S. (2009). Using blogs to enhance critical reflection and community of practice. Educational Technology \& Society, 12(2), 11-21. Retrieved December 27, 2010, from http://www.ifets.info/journals/12_2/2.pdf.

Suad Al Waely was born in Baghdad- Iraq, Al Waely holds a B. A. in Arabic language literature, from University of Baghdad, Baghdad, Iraq, 1991. Her M.A. in Methods of teaching Arabic language from University of Baghdad, Baghdad, Iraq, 1996. Al Waely received her Ph. D. in methods of teaching Arabic language from University of Baghdad, Baghdad, Iraq, 1998.

She is now an assistant professor at Hashemite University in Jordan. Prior to joining Hashemite University, she worked as an assistant professor at Baghdad University in Iraq for twelve years. Her research interests concentrate on teaching Arabic methods, teacher training, language skills, and instructional technology.

Ibtehal M. Aburezeq was born in Suadi Arabia. Aburezeq holds a B. A. in Arabic language literature, from University of Jordan, Amman, Jordan, 1995. Her M.A. in curriculum and instruction from University of Jordan, Amman, Jordan, 1999. Aburezeq received her Ph. D. in curriculum \& instruction from University of Washington, Washington State, USA, 2006.

She is now the Dean of Student Affairs and the Dean of College of Education at Al Ain University of Science and Technology, UAE. Prior to joining Al Ain University, she worked as an assistant professor at Hashemite University in Jordan for three years. Her research interests concentrate on curriculum and teaching methods of languages in general and Arabic language in particular. She also conducts research on instructional technology topics, and pre service students practicum programms. 